\title{
Removal of Hg II and Cu II Ions from Aqueous Solution Using Activated Carbon Produced from Palm Fruit Fibre
}

\author{
Onu Chibuike E. ${ }^{1} \quad$ Okeke Onyeka $^{1} \quad$ Ezeh Ernest $^{2} \quad$ Aniobi C. C. ${ }^{3} \quad$ Orji Nkechi J. ${ }^{4}$ \\ 1.Plastic Production Unit, Scientific Equipment Development Institute, Enugu \\ 2.Chemical Engineering Department, Nnamdi Azikiwe University, Awka \\ 3.Department of Community Medicine, University of Nigeria, Nsukka \\ 4.Pure and Industrial Chemistry Department, University of Nigeria, Nsukka
}

\begin{abstract}
Studies were carried out to evaluate the removal of $\mathrm{Hg}$ II and $\mathrm{Cu}$ II ions from aqueous solution using activated carbon produced from palm fruit fibre. Appropriate analytical procedure and instrumentation was applied in carrying out the batch adsorption experiment. Increase in adsorbents dosage and solution temperature was found to significantly increase the removal of the two metal ions from aqueous solution. Increase in the initial concentration of the adsorbate significantly reduced the adsorption efficiency of the adsorbent due to increase in the adsorbate concentration in the solution to the unchanging number of adsorption sides on the adsorbent. The solution $\mathrm{pH}$ and contact time of the adsorbate and adsorbent reached maximum removal efficiency at 6.0 and $45 \mathrm{~min}$ respectively revealing the dependency of effective adsorption by activated carbon on these factors. The $\Delta \mathrm{S}$ and $\Delta \mathrm{H}$ of the adsorption were positive showing an endothermic adsorption process. The decrease in Gibbs free energy of adsorption with increase in adsorption efficiency of the activated carbon shows that effective adsorption of adsorbates favours high temperatures.
\end{abstract}

Keywords: Activated carbon, Heavy metals, $\mathrm{Cu}$ II ions, $\mathrm{Hg}$ II ions Adsorption efficiency and Aqueous solution. DOI: $10.7176 / \mathrm{CMR} / 11-6-05$

Publication date: August 31st 2019

\section{INTRODUCTION}

With an increasing global usage and a growing demand for high purity water is fast becoming one of the most natural resources used by humans. Essential for the survival of life on earth, the effective management distribution, storage, recycling and purification of water are critical to ensure the sustainable use of this resource into the future. Water is necessary for many human activities including agriculture, industrial processes, recreation and most importantly consumption. Water pollution due to toxic metals and organic compounds remains a serious environmental and public problem. Nowadays water pollution by heavy metals is fast growing due to natural processes and increasing human activities which include mining, agriculture and manufacturing industrial (Moyo et al., 2013).

Heavy metals are non-biodegradable and hence cannot be detoxified biologically. Heavy metals such as mercury, lead, calcium, arsenic are very toxic to living organism at very low concentrations and have the tendency to accumulate in the body for as long as possible (Mubarak et al., 2012).

According to Mubarak et al., (2012) metals such as copper and zinc although required by the body in trace amounts can be toxic to the body at high concentrations. Exposure to heavy metals such as mercury, copper, lead, calcium, arsenic and chromium is through ingestion of food, water, dust and particular inhalation and vehicular emission.

According to Rajesh Kumar et al., (2004), the acute and chronic symptoms of heavy metal symptoms include poor development of foetus, memory loss, sleep disabilities, neuropathy, depression, respiratory disorders, kidney and liver failures, vomiting, weakened immune system, stomach ulcer, constipation, vomiting and damages to the central nervous system.

Cohen and Costa, (2010) reported that chronic exposure to copper particularly results to Wilson disease, a genetic disorder that causes abnormal accumulation of copper in body tissues

Indeed, years of increased industrial, agricultural and domestic activities have resulted in the generation of large amount of waste water containing a number of toxic pollutants which are polluting the available fresh water continuously. With the realization that pollutants present in water adversely affect human and animal life, domestic and industrial activities, pollution control and management is now a high priority.

Through serious efforts of researchers all over the world in the field of pollution control and management, a number of methodologies with varying degrees of successes have been developed to manage water pollution especially by heavy metals.

Examples of such water pollution treatment methodologies include coagulation, flock flotation, chemical oxidation, disaffection, membrane process, sedimentation and adsorption (Bhatnagar and Minocha, 2006).

Among various available technologies for water pollution control, adsorption process is considered the best compared to other methods because of its convenience, ease of operation and simplicity of design. Adsorption is 
generally described through isotherm, that is the amount of adsorbate on the adsorbent as a function of its pressure (if gas) or concentration (if liquid) at constant temperature (Debrowski, 1999).

Therefore adsorption is a surface phenomenon that results from unsaturated and unbalanced molecular forces on a solid surface that are satisfied by attracting adsorbate molecules, atoms or ions resulting in a higher concentration of these particles on its solid surface relative to the bulk solution.

According to Bhatnagar and Minocha, (2006), adsorption process has been widely used for the removal of solute from solutions and gases from an atmosphere and that the extent of adsorption depends on the nature of the adsorbent especially its porosity and surface area. A fundamental important characteristics of good adsorbents is their high porosity and consequently larger surface area with more specific adsorption sites.

Accordingly a better adsorbent is the one with large surface area and which requires less time for adsorption equilibrium (Manoochehri et al., 2012). Activated carbon has undoubtedly been the most popular and widely used adsorbents for the adsorption of organic and inorganic pollutants in aqueous solutions.

Activated carbon is produced by a process consisting of raw materials dehydration and carbonization, followed by activation. The starting material is dehydrated and carbonized by slowly heating in the absence of air. Activation is essentially a two phase process requiring burning of amorphous decomposition products (tars), plus enlargement of pores in the carbonized material (Bhatnagar and Minocha, 2006; Thommes, 2010).

The resulting product obtained is known as activated carbon and generally has a very porous structure with a large surface area ranging from $600-2000 \mathrm{~m}^{2} / \mathrm{g}$ (Mengistie et al., 2008). Activated carbon adsorption can be physical or chemical. Physi-sorption occurs through Vander-waals attraction and is a reversible exothermic process that is not site specific and can result in the multi-cellular thickness of the adsorbed phase (Rutheva, 1994). Chemi-sorption forces arise from redistribution of electrons between the adsorbent and adsorbate, resulting in a site specific irreversible chemical bond and can result in unimolecular thickness of the adsorbed phase (Suzuki, 1993). Activated carbon can be considered as a material of phenomenal surface made off millions of pores comparable to a molecular sponge.

The use of activated carbon is conditioned to its surface chemistry and its hetero atoms content (elements such as sulphur, nitrogen and oxygen ) which gives the material different acidic or basic characteristic, which influences these adsorption properties (Nahil and Williams, 2012). In the carbon structure, the main functional groups which in general are considered responsible for the uptake of pollutants include carboxyl, carboxyl, phenols, lactones, quinones beside others. The unique adsorption properties of activated carbon can be significantly influenced by these functional groups. The nature and concentration of surface functional groups may be modified by suitable thermal or chemical of activated carbon for specific contaminants removal (Bhatnagar et al., (2013).

The efficiency of activated carbon as an adsorbent for diverse types of pollutants which includes organic compounds, heavy metals and inorganic pollutant's are well documented (Hossler and Cheremisinoff, 1980; Yang 2003). Activated carbon has become the standard adsorbent for the reclamation of municipal and waste industrial work water to portable water quality.

According to Manoochehri et al., (2012) activated carbon has been employed in the removal of many toxic metal ions from aqueous solutions. Activated carbon can be prepared from a variety of carbon containing materials such as coke, olive stones, pinewood, rice hulls, palm shell, Pinus carbaea, saw dust, anthracite, palm kernels, Moringa oleifera seed husks, coconut shell and palm fruit bunch particles (Bhatnagar and Minocha, 2006). The application of palm fruit fibre as a adsorbent materials, which is readily available, cheap and a waste product of agricultural produce presents a strong potential due to its main lignocellulosic contents which contains functional groups as binding sides for heavy metals, organic and inorganic compounds (Bhatnagar et al., 2013).

Hence, studies was carried out to investigate the removal of $\mathrm{Hg}$ II and $\mathrm{Cu}$ II ions from aqueous solution using activated carbon produced from palm fruit fibre.

\section{MATERIALS AND METHODS PREPARATION OF THE BIOMASS}

The palm fruit fibre was collected from farms and households within Awka South L.G.A. in Anambra State, Nigeria. It was washed thoroughly with water and dried for 96 hours. The dried biomass was sieved using $100-$ $300 \mu \mathrm{m}$ analytical sieves. The sieved samples were subsequently washed with $0.01 \mathrm{M} \mathrm{HCl}$ in order to remove any interfering substances that might be in the biomass.

\section{PREPARATION OF ACTIVATED CARBON}

The activated carbon was prepared according to the reported procedure of (El-Nemr et al., 2007, Esmaeli et al., (2010).

The palm fruit fibre $(300 \mathrm{~g})$ was weighed into a clear dry beaker containing $200 \mathrm{ml}$ of $95 \% \mathrm{H}_{2} \mathrm{SO}_{4}$ for about 24 hours and was followed by refluxing in a fume hood for 4 hours.

After cooling, the reaction mixture was filtered with de-ionized water and soaked in $1 \% \mathrm{NaHCO}_{3}$ solution to 
neutralize any remaining acid. The sample biomass was then washed with de-ionized water until a neutral $\mathrm{pH}$ between 6 and 7 was obtained. The sample was then dried overnight in an oven at $150^{\circ} \mathrm{C}$ and subsequently kept in a clean glass bottle until use.

\section{ADSORBATE PREPARATION}

The preparation of the adsorbates was carried out in accordance with the reported procedures of Mengistie et al., (2008). Stock solution of $1000 \mathrm{mg} / 1 \mathrm{Hg}$ II and $\mathrm{Cu}$ II ions were respectively prepared by dissolving $\mathrm{HgCl}_{2}$ and $\mathrm{CuSO}_{4}\left(\right.$ Merck, South Africa) in ultra pure water (resistivity $>18 \mathrm{~m} \Omega \mathrm{cm}^{-1}$ ) and acidified accordingly with $5 \mathrm{ml}$ of Conc. $\mathrm{HNO}_{3}$ to prevent hydrolysis of the prepared solutions.

Progressive dilution procedure of the stock solutions was employed in the preparation of the working solutions. The $\mathrm{pH}$ of the working solutions were adjusted to required values with $0.1 \mathrm{M} \mathrm{NaOH}$ or $0.1 \mathrm{M}$ HCL. The entire chemicals used were of analytical reagent grade.

\section{BATCH ADSORPTION STUDIES}

A weighed amount of the activated carbon was introduced into the stoppered reagent bottles of various concentrations with $100 \mathrm{ml}$ aqueous solutions of $\mathrm{Hg}$ II ion and $\mathrm{Cu}$ II ions respectively. The suspensions were shaken at room temperature using a chemical shaker for a proscribed time at $160 \mathrm{rpm}$. The solutions were filtered using whatmann 42 filter paper and the residual concentrations of the metal ions respectively determined by flame atomic adsorption spectrophotometer at $210 \mathrm{~nm}$.

The effect of concentration $(25-90 \mathrm{mg} / 1)$, adsorbent dosage $(0.3-1.2 \mathrm{~g})$, solution $\mathrm{pH}(3.0-12.0)$, contact time $(15-60 \mathrm{~min})$ and temperature $\left(30-120^{\circ} \mathrm{C}\right)$ were studied. Blank solution was treated similarly and the recorded concentration at the end of each procedure was taken as the initial one.

The percentage of the removed metal ion $(\mathrm{R} \%)$ in the solution was calculated using

$$
R \%=\frac{C o-C e}{C o} \times \frac{100}{1}------------------------------------(1)
$$

Were Co is the initial concentration of the metal ion while $\mathrm{Ce}$ is the equilibrium concentration of the metal ion. Calculation of thermodynamic parameters;

The values of $\Delta \mathrm{H}$ and $\Delta \mathrm{S}$ were respectively calculated from the slope and intercept of the linear Vant's Hoff plot using the relation.

$$
\begin{aligned}
& \operatorname{LnKd}=\frac{\Delta S}{R}-\frac{\Delta H}{R T} \\
& \text { Where } \Delta \mathrm{S} \quad=\quad \text { entropy change for the process } \\
& \Delta \mathrm{H}=\text { enthalpy change for the adsorption process } \\
& \mathrm{R} \quad=\quad \text { gas constant } \\
& \mathrm{T}=\quad \text { absolute temperature }
\end{aligned}
$$

The distribution coefficient $(\mathrm{Kd})$ of the metal ions on the activated carbon was calculated using the equation.

$K d=\frac{C o-C e}{C o} \times \frac{V}{M}(m g / l)------------------------------------(3)$

The changes in Gibbs free energy $(\Delta \mathrm{G})$ for the specific adsorptions were calculated using the equation;

$$
\Delta \mathrm{G} \quad=\quad-\mathrm{RT} \text { LnKd }
$$

Where the symbols have their usual significance.

\section{RESULTS AND DISCUSSION}

Effect of concentration.

Table 1 shows that as the concentration of $\mathrm{Hg}$ II and $\mathrm{Cu}$ II ions were increased in the aqueous solutions from 25 to $90 \mathrm{mg} / 1$, the removal efficiency of the metal ions by the adsorbent (activated carbon) decreased from 84.713 to $50.960 \%$ for $\mathrm{Hg}$ II ions and 92.456 to $64.882 \%$ for $\mathrm{Cu}$ II ions.

Table I: Percentage adsorption efficiency of $1.2 \mathrm{~g}$ of the adsorbent at varying concentrations of the adsorbates.

\begin{tabular}{|c|c|c|}
\hline Concentration & $\mathbf{R \%} \mathbf{~ H g}$ & $\mathbf{R \%} \mathbf{~ u}$ \\
\hline 25 & 84.713 & 92.456 \\
\hline 50 & 73.064 & 85.721 \\
\hline 75 & 61.522 & 76.009 \\
\hline 90 & 50.960 & 64.882 \\
\hline
\end{tabular}


Fig. 1 shows a graphical decline in the adsorption efficiency of activated carbon as the concentrations of the adsorbate ( $\mathrm{Hg}$ II ions and $\mathrm{Cu}$ II ions) were increased in the aqueous solution.

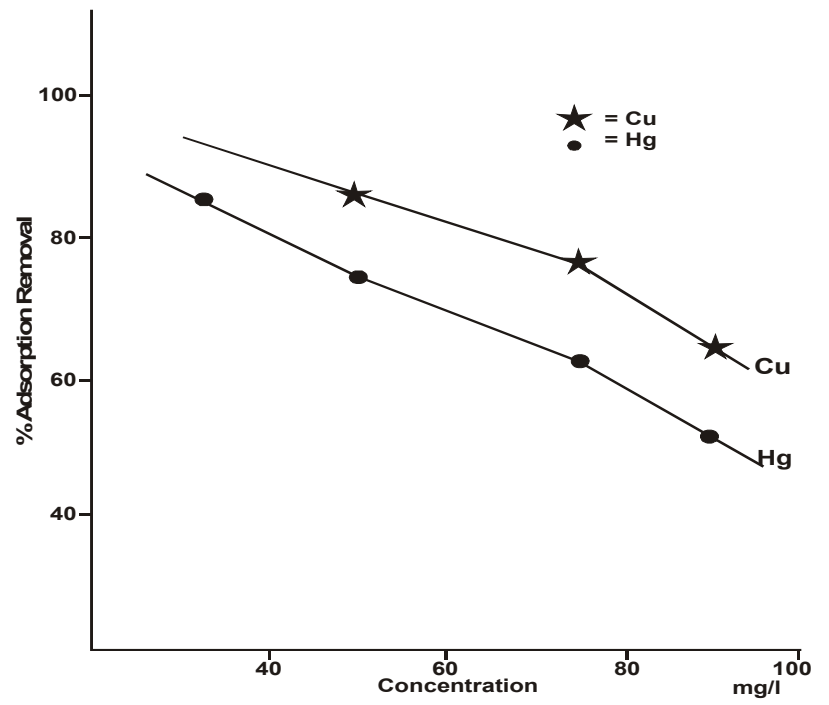

Fig. 1: A graphical representation of the adsorption efficiency of activated carbon at varying concentrations of the adsorbates in the aqueous solution.

The phenomenon could be attributed to the availability of the same amount of adsorbent site for the various concentrations of the adsorbates in the aqueous solution. It was observed that $\mathrm{Hg}$ II ions were poorly adsorbed in the activated carbon compared to $\mathrm{Cu}$ II ions because it is more solvated in aqueous solutions making its adsorption more difficult.

The higher electropositivity of $\mathrm{Cu}$ compared to $\mathrm{Hg}$ could also have accounted for its higher percentage adsorption by the adsorbent.

Daga and Metha (2010) reported similar observation for a varied concentration of Ni II ions at a fixed adsorbent dosage.

\section{EFFECT OF DOSAGE}

Table 2 shows that as the adsorbent's dosage were increased from 0.3 to $1.2 \mathrm{~g}$ in the aqueous solutions, the removal efficiency of the activated carbon increased from 74.691 to $90.722 \%$ for $\mathrm{Hg}$ II ions and 80.13 to $95.570 \%$ for $\mathrm{Cu}$ II ions.

Table 2: Percentage adsorption efficiency of activated carbon at varying dosages.

\begin{tabular}{|c|c|c|}
\hline Dosage (g) & $\mathbf{R \% ~ H g}$ & $\mathbf{R \%} \mathbf{C u}$ \\
\hline 0.3 & 74.691 & 80.113 \\
\hline 0.6 & 82.047 & 84.971 \\
\hline 0.9 & 87.108 & 90.625 \\
\hline 1.2 & 90.722 & 95.570 \\
\hline
\end{tabular}

Fig. 2 shows a graphical illustration of the increased adsorption of the heavy metal ions from the aqueous solution with increase in activated carbon dosage. 


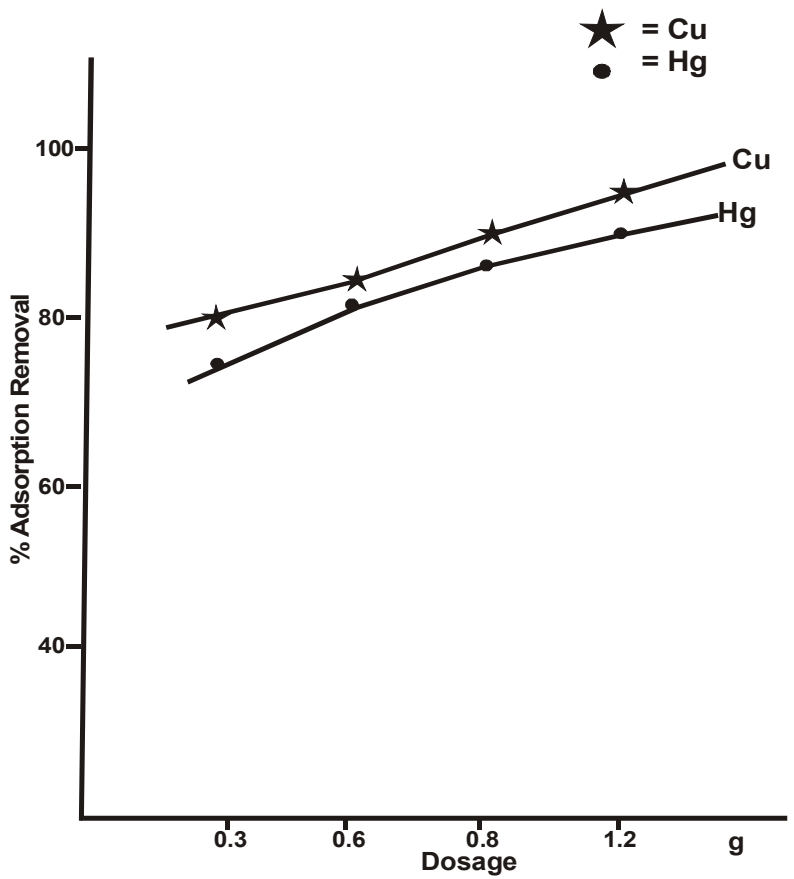

Fig. 2: A graphical representation of adsorption efficiency of activated carbon at varying adsorbent dosages.

This phenomenon could be attributed to a greater availability of adsorption sites or surface area of the activated carbon, thus enabling faster and easier penetration of the heavy metal ions unto these adsorption sites. The result of this study compared favourably with the findings of Eposito et al., (2011) in which they reported that increase in adsorbents dosage in aqueous metallic solutions increases adsorption due to more surface areas and functional groups being available on the adsorbent.

Olorundare et al., (2012) observed an increase in the adsorption efficiency of activated carbon for heavy metal $(\mathrm{Pb})$ in aqueous solution from 65 to $89 \%$ and this agreed with the results of this study. Kumar et al., (2014) equally reported an increase in adsorption of Cd II and Zn II ions from aqueous solution with increase in adsorbents dosage.

\section{Effect of pH}

The $\mathrm{pH}$ is one of the most important factors governing the adsorption of metal ions from the aqueous solutions which affects the functional groups protonation and also metal ions adsorption by the adsorbents.

Table 3: Percentage adsorption efficiency of activated carbon at $1.2 \mathrm{~g}$ dosage and varying $\mathrm{pH}$

\begin{tabular}{|c|c|c|}
\hline $\mathbf{p H}$ & $\mathbf{R \%} \mathbf{H g}$ & $\mathbf{R \%} \mathbf{C u}$ \\
\hline 3.0 & 83.803 & 90.392 \\
\hline 6.0 & 89.071 & 93.846 \\
\hline 9.0 & 85.482 & 90.050 \\
\hline 12.0 & 84.245 & 88.603 \\
\hline
\end{tabular}

Modin et al, (2011) stated that the $\mathrm{pH}$ is an important factor affecting the sorption of heavy metals and in general sorption of metallic species increases with increase in $\mathrm{pH}$ to a certain range.

Table 3 shows that the adsorption of $\mathrm{Hg}$ II and $\mathrm{Cu}$ II ions from the aqueous solution reached maximum saturation capacity at $\mathrm{pH}$ of 6.0 with 89.071 and $93.846 \%$ respectively. In aqueous solution, copper and mercury species could be present in the form of $\mathrm{Cu}^{2+}, \mathrm{Cu}(\mathrm{OH})^{+}, \mathrm{Cu}(\mathrm{OH})_{2}, \mathrm{Cu}(\mathrm{OH})_{3}^{-}$and $\mathrm{Hg}^{2+}, \mathrm{Hg}(\mathrm{OH})^{+}, \mathrm{Hg}(\mathrm{OH})_{2}, \mathrm{Hg}(\mathrm{OH})_{3}^{-}$ respectively.

$\mathrm{Cu}^{2+}$ and $\mathrm{Hg}^{2+}$ are usually the dominant species at $\mathrm{pH}<7$. The graphical illustration of the effect of $\mathrm{pH}$ adsorbents is shown in Fig. 3. 


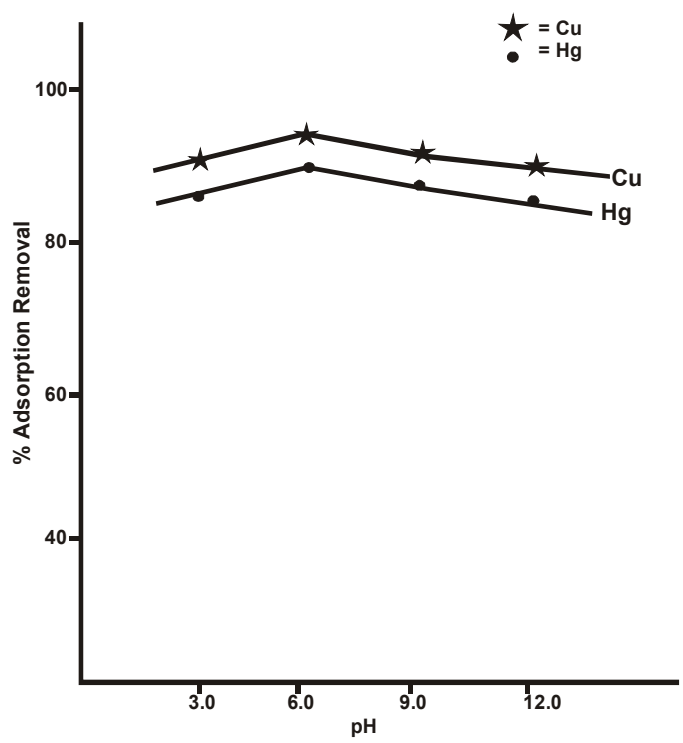

Fig.3: A graphical representation of adsorption efficiency of activated carbon at varying $\mathrm{pH}$.

At $\mathrm{pH}$ ranges of 3.0 and 6.0 the surface of activated carbon becomes negatively charged hence increases its adsorption capacity of positively charged metal ions though electrostatic forces of attraction. The results of the study compares favourably with the findings of Mengistie et al., (2008) who reported an increase in adsorption efficiency of activated carbon for $\mathrm{Pb}$ II ions in aqueous solution as it was made less acidic.

\section{EFFECT OF CONTACT TIME}

Table 4: Percentage adsorption efficiency of activated carbon at varying contact time.

\begin{tabular}{|c|c|c|}
\hline Time (min) & R\% Hg & R\% Cu \\
\hline 15 & 78.205 & 81.103 \\
\hline 30 & 83.636 & 85.725 \\
\hline 45 & 89.144 & 93.552 \\
\hline 60 & 86.377 & 90.470 \\
\hline
\end{tabular}

Table 4 shows that the adsorption of $\mathrm{Hg}$ II and $\mathrm{Cu}$ II ions from the aqueous solution became enhanced in the first 30 mins and attained saturation capacity at $45 \mathrm{~min}$ after which the adsorption of the metal ions decreased. Hence by increasing the contact time of the adsorbate and adsorbent in the aqueous solution from 15 to $45 \mathrm{mins}$ the adsorption capacity of the adsorbent for $\mathrm{Hg}$ II and $\mathrm{Cu}$ II ions increased from 78.205 to $89.144 \%$ and 81.103 to $93.552 \%$ respectively. The adsorption efficiency of the activated carbon decreased to $86.577 \%$ for $\mathrm{Hg}$ II ion and $90.470 \%$ for $\mathrm{Cu}$ II ions as the contact time increased to 60mins as shown in Fig. 4.

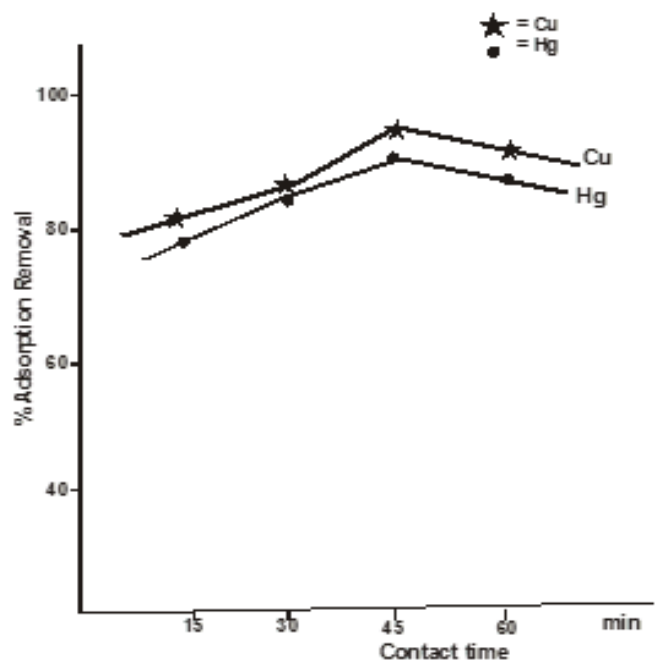

Fig. 4: A graphical representation of adsorption efficiency of activated carbon at varying contact time.

According to Li et al., (2008), increase in contact time of the adsorbate and adsorbent in aqueous metallic solutions 
in the initial stages of adsorption usually enhances the external surface area of the adsorbent for adsorption followed by a slower adsorption and internal diffusion process which may be the rate determining step.

Table 5: Kinetics of adsorption of $\mathrm{Hg}$ II and $\mathrm{Cu}$ II ions at varying time

\begin{tabular}{|c|c|c|}
\hline Time (min) & Ln Co/Ce Hg & Ln Co/Ce Cu \\
\hline 15 & 1.553 & 1.583 \\
\hline 30 & 1.680 & 1.804 \\
\hline 45 & 1.853 & 1.926 \\
\hline 60 & 1.979 & 2.163 \\
\hline
\end{tabular}

The reaction rates of the adsorption of $\mathrm{Hg}$ II and $\mathrm{Cu}$ II ions on the surface of activated carbon at varying contact time was of the first order following a plot of $\mathrm{Ln} \mathrm{Co} / \mathrm{Ce}$ against time as shown in fig. 5.

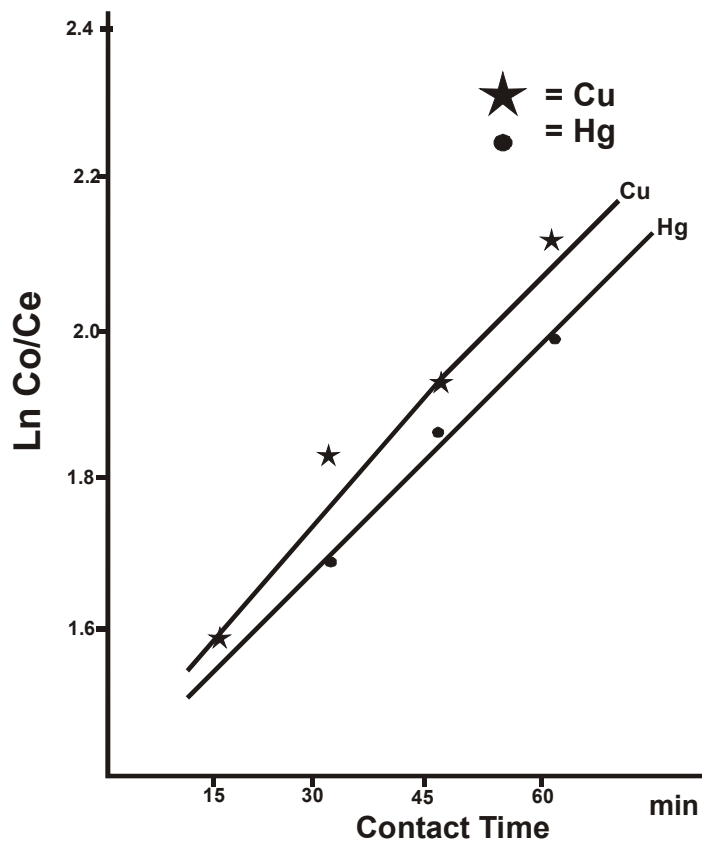

Fig. 5: A graphical representation of the kinetics of adsorption of $\mathrm{Hg}$ II and $\mathrm{Cu}$ II ions at varying contact time.

The mathematical evaluation of the kinetics of adsorption indicates that adsorbates uptake by the adsorbents at solid solution interface is usually time dependent.

Effect of Temperature

Table 6: Percentage adsorption efficiency of activated carbon at varying temperature.

\begin{tabular}{|c|c|c|}
\hline Temp $^{\mathbf{0}} \mathbf{C}$ & $\mathbf{R \% ~ H g}$ & $\mathbf{R \%} \mathbf{C u}$ \\
\hline 30 & 83.742 & 87.662 \\
\hline 60 & 89.816 & 91.107 \\
\hline 90 & 92.217 & 94.233 \\
\hline 120 & 93.962 & 96.770 \\
\hline
\end{tabular}

Table 6 shows that increase in temperature increased the percentage removal of $\mathrm{Hg}$ II ions from 85.742 to 93.962 and $\mathrm{Cu}$ II ions from 87.662 to 96.770 . The effects of temperature variation on the adsorption of $\mathrm{Hg}$ II and $\mathrm{Cu}$ II ions from aqueous solution have been shown in Fig. 6. 


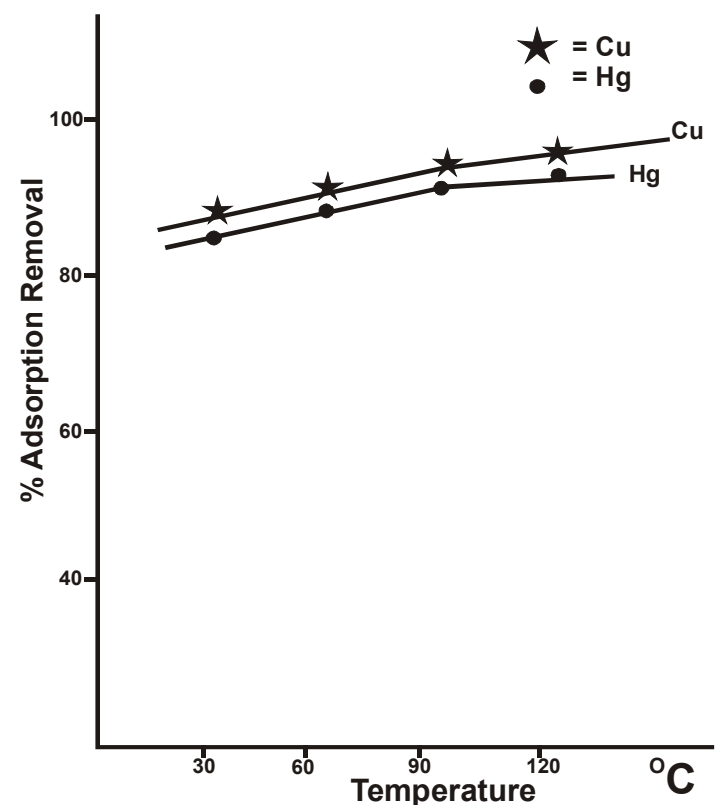

Fig. 6: A graphical representation of the adsorption efficiency of activated carbon at varying temperature.

Result of Table 6 shows that the extent of adsorption for both metal ions increased with increase in temperature indicating the adsorption process to be endothermic. Since diffusion is on endothermic process it would be expected that an increase in solution temperature would result to the enlargement of the pore size due to activated diffusion causing the microspores to widen and deepen and create more surfaces for adsorption.

Table 7: Adsorption studies of $\mathrm{Hg}$ II and $\mathrm{Cu}$ II ions on the surface of the adsorbent as a function of temperature.

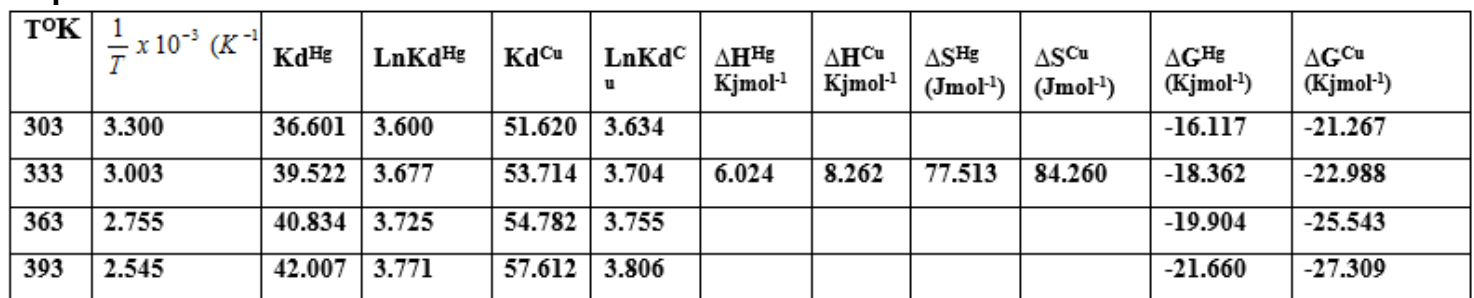

Table 7 shows that the decrease in $\Delta \mathrm{G}$ values from -16.117 to $-21.360 \mathrm{kjmol}^{-1}$ for $\mathrm{Hg}$ II ions and -21.267 to -27.309 $\mathrm{kjmol}^{-1}$ for $\mathrm{Cu}$ II ions with increase in temperature from 303 to $393 \mathrm{~K}$ suggests that the adsorption of the two heavy metal ions by the adsorbent was favourable at higher temperatures. The result equally indicates that the white the adsorption process was spontaneous and therefore increases the affinity of the metals ions on the surface of the adsorbent. A plot of $L n K d v s \frac{1}{T}$ gave a straight line graph and evaluation of $\Delta \mathrm{S}$ from the plot gave 77.513 and 84.260 $\mathrm{Jmol}^{-1}$ for $\mathrm{Hg} \mathrm{II}$ and $\mathrm{Cu}$ II ions respectively. 


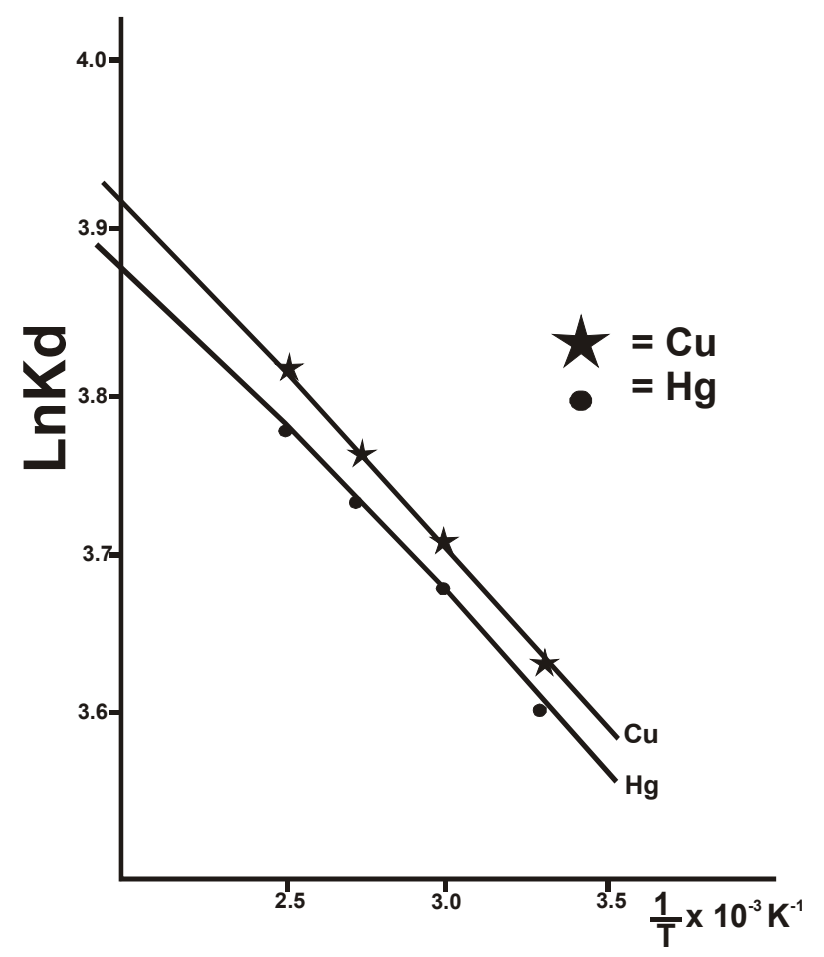

Fig. 7: A graphical representation of the adsorption of $\mathrm{Hg} \mathrm{II}$ and $\mathrm{Cu}$ II ions as function of temperature.

The positive values of $\Delta \mathrm{S}$ indicate an increase in randomness at the solid solution surface during the fix action of $\mathrm{Hg}$ II and $\mathrm{Cu}$ II ions in the active sites of the adsorbent.

The enthalpy of adsorption $(\Delta \mathrm{H})$ of $\mathrm{Hg}$ II ions and $\mathrm{Cu}$ II ions estimated from the plot were 6.024 and $8.262 \mathrm{kjmol}^{-}$

${ }^{1}$ respectively. The positive values of the enthalpy of the entire adsorption process indicates that the reaction on the surface of the activated carbon was endothermic

\section{CONCLUSION}

Activated carbon produced from palm fruit fibre has shown great potential in its use in the adsorption of the metal ions ( $\mathrm{Hg}$ II and $\mathrm{Cu}$ II ions) from aqueous solution.

The adsorption of the two metal ions from aqueous solution was found to decrease with increase in initial concentrations of the metal ions indicating the applicability of the bio-sorbent (palm fruit fibre) at lower concentrations.

Adsorption equilibrium for the metals was reached in $45 \mathrm{~min}$ and was endothermic based a the calculated value of $\Delta \mathrm{S}, \Delta \mathrm{G}$ and $\Delta \mathrm{H}$.

Adsorption efficiency was found to increase with increase in $\mathrm{pH}$ showing a maximum at 6.0.

Increases in both the adsorbent's dosage and solution temperature were found to increase the percentage removal of the two metal ions from aqueous solution.

\section{REFERENCES}

Bhatnagar A. and Minocha A.K (2006). Conventional and non-conventional adsorbents for the removal of pollutants from water, a review: India Journal of chemical technology, 13:203-217.

Bhatnagar A., Hogland W., Margues M. and Sillan Rao M. (2013). An overview of the modification methods of activated carbon for water treatment applications . Chemical engineering Journal. 219: 499-511.

Cheremisinoff P.N (2000). Carbon adsorption Handbook. Ann Abor Science, MI, 228-234

Cohen M.D and Costa M. (2006) Environmental toxicants; exposures and their health effects. John Wiley and sons Inc. $173-179$.

Daga K. and Mehta R. (2011). Adsorption study of Ni II ions using polyvinyl alcohol coated carbon black as an effective and low cost adsorbent. International journal of chemistry, 3(3): 36-61.

El-Nemr D., Sikaly A.E., Khaled A. and Abdelwahab O. (2007). Removal of toxic chromium IV from aqueous solution by activated carbon based Casuarinas equisetifolia. Chemistry and Ecology, 23(2). 119-129.

Esmaeli A, Ghasemi S. and Sohrabi Rao I. (2010). Biosorption of copper from waste water by activated carbon preparation from Alga Sargassum sp. Natural product research, 24(4): 341-348. 
Esposito I., Pagnanelli F., Lodi A., Soliso C. and Veglio F. (2011). Biosorption of heavy metals by Sphaerotilus natans, an equilibrium study at different $\mathrm{pH}$ and biomass concentration. Journal of Hydrometallurgy 60(1); 129-141.

Kumar P.R., Swathanthra P.A., Bossaa Rao V.V. and Mohan Rao S.R. (2004). Adsorption of calcium and zinc ions from aqueous solution using low cost adsorbents. Journal of Applied sciences, 14(13): 1372-1378.

Li W., Zhang, Pang J., Zhang S. and Guo S. (2008). Tobacco stems as a low cost adsorbent for the removal of Pb II from waste water: An equilibrium and kinetic studies. Industrial Crops and Products, 28(3):294-302.

Manoochehri M., Khorsand A. and Hashemi F. (2012). Role of modified activated carbon by $\mathrm{H}_{3} \mathrm{PO}_{4}$ or $\mathrm{K}_{2} \mathrm{CO}_{3}$ from natural adsorbent for the removal of Ph II from aqueous solution. Carbon letters 13 (12): 115-120.

Mengistie A.A, Siva Rao T., Presada Rao A.V. and Singanan M. (2008). Removal of lead II ions from aqueous using activated carbon from Militia ferruginea plant leaves. Bull Chem. Soc. 22(3). 349-360.

Modin H., Person K.M. Andersson A. and Van Praagh M. (2011). Removal of metals from land filled leachate by sorption to activated carbon bone meal and Iron fines. J. Hazard mater, 189:749-784.

Moyo M. Chikazaza L, Nyaminda B.C. and Guyo U. (2013). Adsorption Batch studies on the removal of Pb II using maize tassel based activated carbon. International Journal of physical science research, 17: 303-317.

Mubarak N.M., Daniel S., Khalid M. and Tan J. (2012). Comparative Study of functionalized and non functionalized carbon nanotube for the removal of copper from polluted water. International Journal of chemical and environmental engineering, 3:1-4.

Nahil M.A. and Williams P. (2012). Pore characteristics of activated carbon from phosphoric acid chemical activation of cotton stalks. Biomass and Bioenergy, 37(1): 142-149.

Olorundare O.F., Krause W.M., Okonkwo J.O. and Mamba B.B. (2012). Potential application of activated carbon from maize tassel for the removal of heavy metals in water. Physics and chemistry of the earth, 50-52: 104110.

Ruthevan O.M (1994). Principles of adsorption and adsorption process. John Wiley, New York S. 332 - 347.

Suzuki M. (1993). Fundamentals of adsorption. Elsevier publishers 381-386.

Thommes M. (2010). Physical adsorption characterization of nanoporous materials. Chemieingenieur Technik, 82(7): 1059-1067.

Yang R.T. (2003). Adsorbents Fundamentals and Application. John Wiley \& Sons. Inc, Hoboken New Jessey. 143-146. 